\title{
EFFECT OF WEAVE STRUCTURE ON THERMO-PHYSIOLOGICAL PROPERTIES OF COTTON
} FABRICS

\author{
Sheraz Ahmad ${ }^{1}$, Faheem Ahmad $^{1}$, Ali Afzal ${ }^{1}$, Abher Rasheed $^{1}$, Muhammad Mohsin $^{2}$, Niaz Ahmad $^{1}$ \\ ${ }^{1}$ Faculty of Engineering \& Technology, National Textile University, Faisalabad-37610, Pakistan \\ ${ }^{2}$ Centre for Advancement of Textile Engineering and Technology, University of Engineering and Technology Lahore, Faisalabad Campus Faisalabad, Pakistan \\ Email address: itsadeelnaz@hotmail.com
}

\begin{abstract}
:
This paper aims to investigate the relationship between fabric weave structure and its comfort properties. The two basic weave structures and four derivatives for each selected weave structure were studied. Comfort properties, porosity, air permeability and thermal resistance of all the fabric samples were determined. In our research the 1/1 plain weave structure showed the highest thermal resistance making it suitable for cold climatic conditions. The 2/2 matt weave depicted the lowest thermal resistance which makes it appropriate for hot climatic conditions.
\end{abstract}

\section{Keywords:}

cotton, response surface regression, thermo-physiological comfort, weave

\section{Introduction}

Clothing is one of the fundamental needs of humans for protection from external environment. People's selection of clothing is based on their needs and desires. However, the preferences of people change with the context: season, climate, age, type of work/activity and so on. Comfort is a basic requirement in clothing selection in all conditions. Comfort can be defined as 'a pleasant state of psychological, physiological and physical harmony between a human being and the environment'[1].

Wicking is the natural property of cotton. It absorbs the perspiration from the body and evaporates the moisture through wicking action throughout the surface of the fabric and keeps the body cooler and dry. Not only the fibre and the yarn but also the woven fabric characteristics such as structural porosity that play an important role in the comfort properties of clothing. In order to understand the effect of woven fabric properties, the geometry of the woven fabric is considered, which depends upon the woven pattern or the weave design of the fabric. The fabric should give comfort to the wearer in terms of good perspiration absorbency and moisture management.

Clothing plays a vital role in thermo-regulatory process as it alters heat and moisture loss from the skin [2]. The clothing comfort depends upon the external climatic conditions along with the type of clothing and fabrics weave structure [2]. The comfort properties of a textile material are generally represented by fabric moisture management, thermal resistance and air permeability. Thermal conductivity is the property of a material that indicates its ability to conduct heat. It is the heat flux (energy per unit area per unit time) divided by the temperature gradient [3]. Moisture management of a fabric is its ability to absorb and transfer moisture through the fabric. Thermal resistance is the evaluation of the material's ability to prevent heat from flowing through it. It is the temperature difference between the two faces of textile structure divided by the resultant heat flux per unit area in the direction of the gradient [4-6]. Air permeability is the measurement of the material's ability to allow air flow through it. It is defined as the rate of air volume flowing through fabric when there is a pressure difference on both sides of the fabric [7].

Every fibre has certain characteristics. Linear density and cross-sectional shape of the fibres affect the thermal properties. The increase in the linear density increases the porosity of the fabric which results in decreased thermal conductivity [8]. Yarn compactness along with the twist factor also affects the thermal resistance of the fabric. With the increase in fabric compactness, the porosity decreases resulting in the increase of thermal resistance [9].

Hearle and Morton [10] explained that the thermal conductivity of a fabric depends upon the air entrapped in it than on the fibre conductivity. Fabrics with high values of air flow are more suitable for summer clothing because they allow more passage of air through them, which means more comfort. The fabric with twist-less fibrous assembly in the weft shows the highest air permeability whereas the fabric with the hollow fibrous assembly in the weft shows the lowest air permeability [11].

Fabric properties like cover factor and thickness also have an impact on the thermal comfort of the fabric. Bilska et al. [12] studied the effect of weave design on thermal comfort properties of the fabric and found that plain fabrics have the highest value of thermal resistance following their compact structure. The compactness of the structure of plain weave reduces the porosity of the fabric, which results in lower thermal conductivity; canvas weave has a better thermal conductivity due to a comparatively open structure; and twill weave has the lowest value of thermal resistance and the highest value of thermal conductivity due to open its structure which has large floats of yarns, which is the cause behind the higher porosity of 
the fabric. Matusiak and Sikorski [13] also studied the effect of weave design on the comfort of the fabric and concluded that it affected the porosity of the fabric. They found that plain weave has less porous structure and has a high value of thermal resistance. Owing to higher porosity value of plain weave, the heat and moisture transfer through it decreases, which makes it comfortable for warm climate. It should be noted that $2 / 2 \mathrm{~S}$ twill and $3 / 1 \mathrm{~S}$ twill have more value of porosity as compared to plain weave and give cool feeling by permitting the passage of sweat and heat through them.

It is evident that the thermo-physiological comfort has an important role in the clothing selection. The objective of this research was to study the effect of fabric weave structure on thermo-physiological comfort.

\section{Experimental}

In the present study, cotton carded ring spun yarns of 37 tex and 28 tex were used to make fabric samples. The yarn properties are shown in Table 1.

Table 1: Properties of yarns

\begin{tabular}{|c|c|c|}
\hline Properties & Weft & Warp \\
\hline Count (tex) & 35.50 & 29.00 \\
\hline C.V of count & 1.53 & 1.80 \\
\hline CLSP & 1920 & 2140 \\
\hline Uniformity (\%) & 9.9 & 10.23 \\
\hline Hairiness & 8.7 & 8.71 \\
\hline Elongation (\%) & 6.9 & 6.0 \\
\hline Tenacity (cN/tex) & 16.26 & 17.04 \\
\hline TPI (twist per inch) & 15.91 & 18.06 \\
\hline
\end{tabular}

The yarns were made at the speed of $17000 \mathrm{rpm}$ by using Marzoli MP-1N ring frame. The drafting system on this ring frame was 3/3 PK 2025 with 42mm ring cup diameter. Trützschler blow room line with multifunction separator SP-MF, clean mat CL-C1, CL-C3 and foreign part separator SP-F were used. Trützschler TL-03 card and TD-03 drawing frame were used for sliver formation and parallazation, respectively. The roving which was fed to the ring frame was made on simplex machine Marzoli FTSDN.

Fabrics with different weave designs having same areal density and cover factor were woven using 37 tex in warp direction and 28 tex in weft direction. The two basic designs selected for this study were plain and the twill weave structures. The four derivatives for each of the selected weave structure were as follows: 1/1 plain, half panama, 1/1 ottoman, 2/2 matt, 2/2 S twill, $3 / 1 \mathrm{~S}$ twill, $2 / 2$ broken twill and 3/1 broken twill fabrics, which were made on an air jet loom by the systematic arrangement of lifting of different group of warp yarns. Three repetitions of each weave structure were prepared. The schematic diagram of the weave structures are shown in Figures 1 and 2.
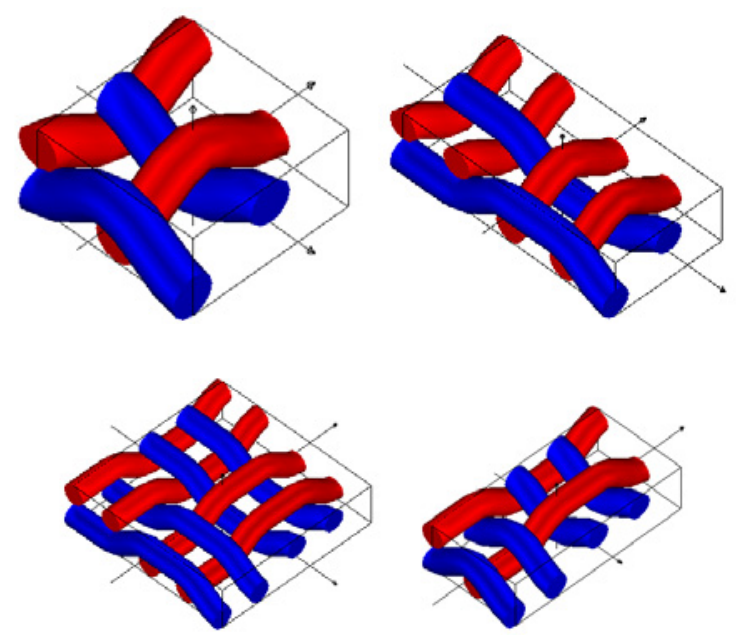

Figure 1. Schematic diagram of plain, ottoman, 2/2 matt and half panama fabric weave structures.
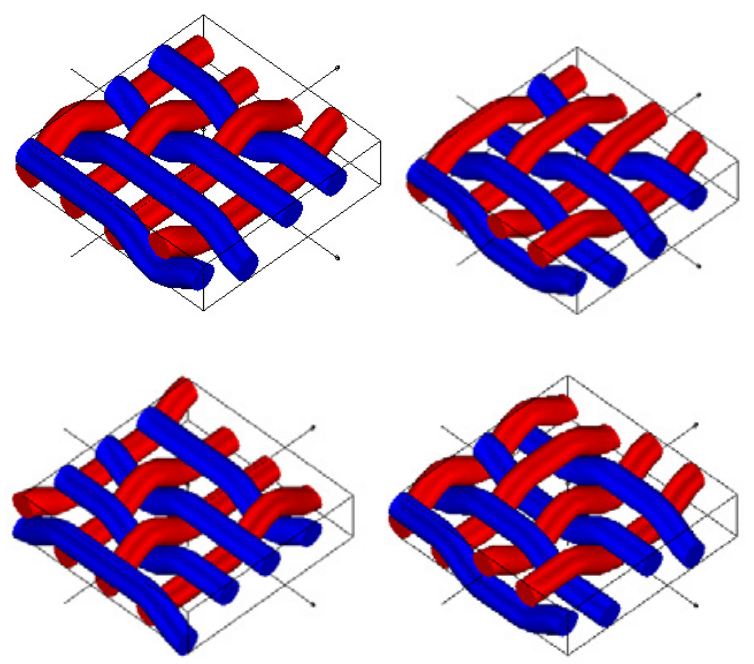

Figure 2. Schematic diagram of $3 / 1 \mathrm{~S}$ twill, $2 / 2 \mathrm{~S}$ twill, $3 / 1$ broken twill and $2 / 2$ broken twill fabric weave structures.

The comfort properties of all the fabric samples were tested and confirmed. The water vapour resistance and thermal resistance of all the fabric samples were measured according to ISO 11092:1993 using sweating-guarded hot plate M259B by SDL Atlas Inc.. The air permeability was also measured according to BSEN ISO 9237:1995 using the M021A of SDL Atlas Inc.

The statistical analysis was done by using Minitab 16. Oneway ANOVA was applied to analyse the significance of weave structures on the comfort properties of the fabric.

\section{Results and discussion}

In this section, the effect of weave structure on comfort properties is discussed. As the comfort properties are generally related to porosity, air permeability and thermal resistance, these parameters are discussed individually. 
Table 2 shows the average values of porosity, air permeability and thermal resistance of all the weave structures.

Table 2: Average values of porosity, air permeability and thermal resistance

\begin{tabular}{|c|c|c|c|}
\hline $\begin{array}{c}\text { Weave } \\
\text { Structure }\end{array}$ & Porosity & $\begin{array}{c}\text { Air } \\
\text { Permeability }\end{array}$ & $\begin{array}{c}\text { Thermal } \\
\text { Resistance }\end{array}$ \\
\hline 1/1 plain & 70,719 & 28,667 & 0,031 \\
\hline half panama & 68,206 & 29,333 & 0,019 \\
\hline 1/1 ottoman & 74,643 & 170,000 & 0,018 \\
\hline 2/2 matt & 74,183 & 130,000 & 0,014 \\
\hline 2/2 S twill & 73,304 & 143,333 & 0,024 \\
\hline 3/1 S twill & 73,785 & 106,667 & 0,025 \\
\hline 2/2 broken twill & 74,219 & 210,000 & 0,023 \\
\hline 3/1 broken twill & 74,175 & 153,333 & 0,029 \\
\hline
\end{tabular}

The one-way ANOVA was applied on the results obtained for porosity, air permeability and thermal resistance. Table 3 shows the R-Sq and p-values for all the parameters.

Table 3: R-Sq and p-values

\begin{tabular}{|c|c|c|c|}
\hline & Porosity & $\begin{array}{c}\text { Air } \\
\text { Permeability }\end{array}$ & $\begin{array}{c}\text { Thermal } \\
\text { Resistance }\end{array}$ \\
\hline R-Sq & 95.07 & 98.60 & 98.70 \\
\hline p-value & 0.001 & 0.001 & 0.001 \\
\hline
\end{tabular}

The results showed that the weave structure has statistically significant correlation with all the selected parameters.

\subsection{Effect of weave on porosity}

Porosity is the free space between the yarns interlaced in the fabric. It is one of the parameters which affect the thermophysiological comfort of the fabric. Figure 3 illustrates the experimental results obtained for fabric porosity and the weave structure.

The relationship between porosity and weave structure is statistically significant at $95 \%$ confidence level. The results showed the highest value of fabric porosity for $1 / 1$ ottoman. This is because of the open structure of this weave, which provides more space between the warp and weft yarns. The open structure is obtained following very few interlacement points of the warp and weft yarns.

\subsection{Effect of weave on air permeability:}

Air permeability is the free passage for air in the fabric which indicates the porosity of the fabric. The higher the porosity, the higher will be the air permeability of the fabric. Experimental results showed that the effect of weave structure was found significant for the air permeability of the fabric ( $p$-value < 0.001 ). The results depict that broken $2 / 2$ twill weave had the highest air permeability followed by Ottoman and 3/1 broken twill weave. This is because of the loose structure as well as the higher fabric porosity. The lowest air permeability value was obtained for plain weave following its compact structure. The individual value plot for air permeability and weave structure is shown in Figure 4.

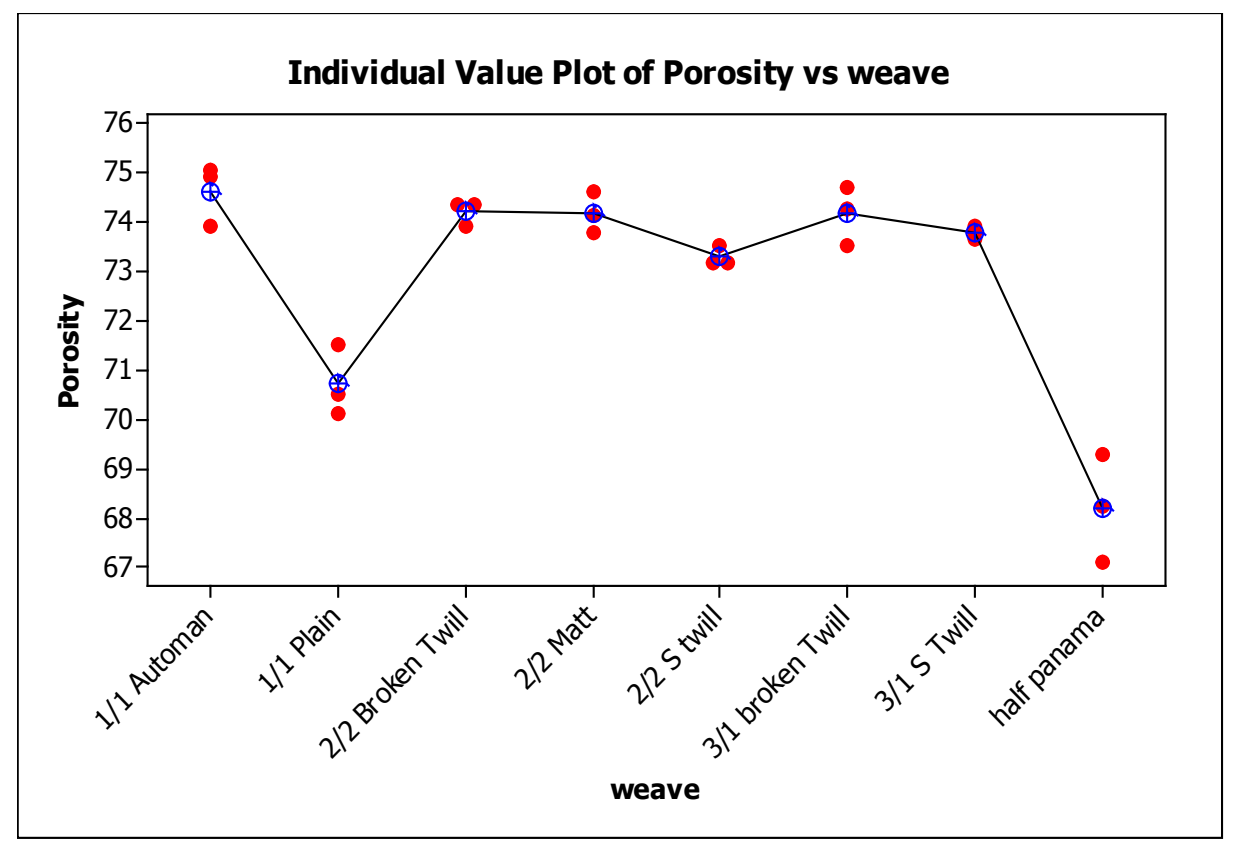

Figure 3: Individual value of porosity vs. weave structure 


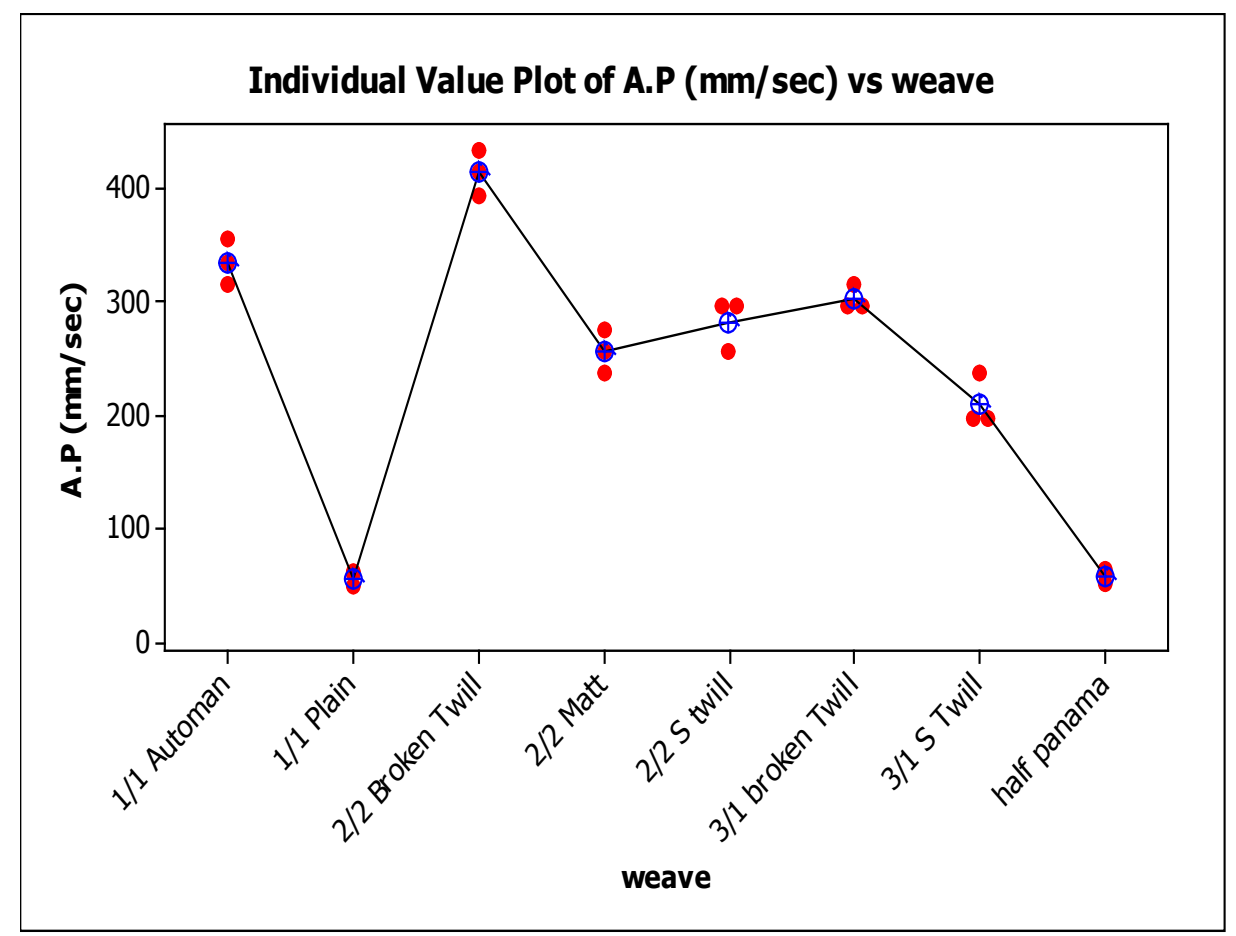

Figure 4: Individual value of air permeability vs. weave structure

\subsection{Effect of weave on thermal resistance (Rct)}

Thermal resistance of a fabric refers to its ability to resist the heat flow through it. The lower the thermal resistance, the better will be the comfort for hot climatic conditions. Experimental results showed that the weave structure has a significant effect on the thermal resistance of the fabric ( $p$-value $<0.001$ ). The results depicted that the $1 / 1$ plain weave has the highest thermal resistance. This is because of the fact that $1 / 1$ plain weave has the maximum yarn interlacing points between warp and weft. High thermal resistance of this weave makes it suitable for cold climatic conditions. On the contrary, 2/2 matt showed the lowest thermal resistance because of its relatively less number of yarn interlacing points between warp and weft. Minimal thermal resistance of 2/2 matt weave makes it appropriate for hot climatic conditions. The individual value plot for air permeability and weave structure is shown in Figure 5.

\section{Conclusions}

The research results proved that weave structure has a statistically significant effect on the porosity, air permeability and thermal resistance of the fabric. The observed parameters contributed to the thermo-physiological comfort of the fabrics. Each weave structure has a specific pattern of yarn interlacing points between the warp and the weft. It can be concluded from the experimental results that the higher the yarn interlacing points, the lower will be the porosity and air permeability which means higher thermal resistance. The experiments illustrated that 1/1 plain weave has

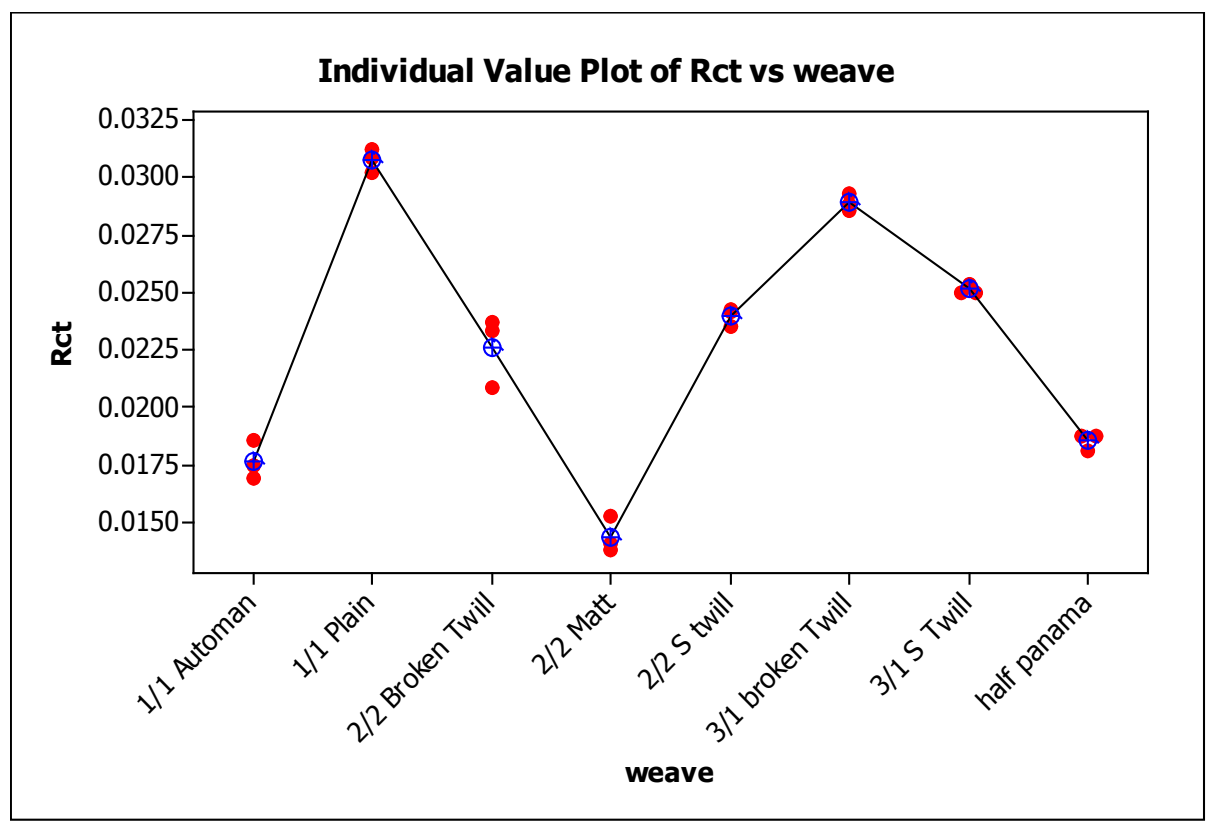

Figure 5: Individual value of thermal resistance vs. weave structure 
the highest thermal resistance among the selected weaves and hence suitable for cold climatic conditions. On the other contrary, 2/2 matt weave demonstrated lower thermal resistance which makes it suitable for hot climatic conditions.

\section{References}

[1] Das, A. and Ishtiaque, S. (2004). Comfort characteristics of fabrics containing twist-less and hollow fibrous assemblies in weft. Journal of Textile and Apparel, Technology and Management, 3, 1-7.

[2] Saville, B. P. (1999). in Physical Testing of Textiles, ed Cambridge, England: Woodhead Publishing Ltd., 1999, pp. 209-243.

[3] Majumdar, A., Mukhopadhyay, S., and Yadav, R. (2010). Thermal properties of knitted fabrics made from cotton and regenerated bamboo cellulosic fibers. International Journal of Thermal Sciences, 49, 2042-2048.

[4] Atlas, S., "M259B Sweating guarded hotplate instruction manual," ed: SDL Atlas, 2010.

[5] Abdel-Rehim, Z. S., Saad, M., El-Shakankery, M., and Hanafy, I. (2006). Textile Fabrics as Thermal Insulators. AUTEX Research Journal, 6(3), 148.

[6] (1994). in Standardization of Guarded hotplate, heat transfer and Water vapour permeability at three laboratories, P. Gibson, M. Auerbach, T. Endrusick, J. Giblo, and W. Teal, Eds., ed Massachusetts: United States army Natick research development and engineering center Natick, 1994.
[7] 11092, I., "ISO 11092, Textile - Physiological effects Measurement of thermal and water vapour resistance under steady state conditions (sweating guarded hotplate test)," ed, 1993.

[8] Varshney, R., Kothari, V., and Dhamija, S. (2010). A study on thermophysiological comfort properties of fabrics in relation to constituent fibre fineness and cross-sectional shapes. The Journal of The Textile Institute, 101(6), 495505.

[9] Tyagi, G., Bhattacharyya, S., Bhowmick, M., and Narang, R. (2010). Study of cotton ring-and compact-spun yarn fabrics: Part II-Effects of spinning variables on comfort characteristics. Indian Journal of Fibre \& Textile Research, 35(2), 128.

[10] Hearle, J. W. S. and Morton, W. E. (2008). Physical Properties of Textile Fibres. 4th ed. Cambridge: Woodhead.

[11] Das, B., Das, A., Kothari, V., Fanguiero, R., and Araujo, M. (2007). Moisture transmission through textiles. Part I: processes involved in moisture transmission and the factors at play, AUTEX Research Journal, (2), 7.

[12] Frydrych, I., Dziworska, G., and Bilska, J. (2002). Comparative analysis of the thermal insulation properties of fabrics made of natural and man-made cellulose fibers. Fibers and Textiles in Eastern Europe, 39(4), 40-44.

[13] Matusiak, M. and Sikorski, K. (2011). Influence of the structure of woven fabrics on their thermal insulation properties. Fibres \& Textiles in Eastern Europe, 19(5), 88. 